Beale, G. H. \& Schneller, M. (1954). J. gen. Microbiol. 11, 57-58.

\title{
A Ninth Variety of Paramecium aurelia
}

\author{
By G. H. BEALE \\ Institute of Animal Genetics, Edinburgh University \\ AND MYRTLE SCHNELLER \\ Department of Zoology, Indiana University, U.S.A.
}

SUMMARY: A new variety of Paramecium aurelia-variety 9-containing two mating types XVII and XVIII, has been identified from seven samples of water collected in Scotland. Variety 9 belongs to the group A varieties in the Sonneborn system of classification, but shows no intervarietal mating reactions.

Paramecium aurelia is readily distinguished from other species of Paramecium by morphological characters, such as the structure and number of micronuclei (see Wenrich, 1928). Within the species $\boldsymbol{P}$. aurelia, however, no fewer than eight distinct varieties or physiological subspecies have been recognized (Sonneborn, 1938, 1942; Sonneborn \& Dippell, 1946a,b). The organisms are classified into one or other of these varieties according to mating behaviour: within a variety, conjugation may be readily brought about between the two mating types which occur in all varieties (except no. 7), and leads to the production of viable progeny; between varieties, by contrast, conjugation may not occur at all, or if it does, the $F_{1}$ hybrids, or the $F_{2}$ progeny derived from them, are non-viable.

Recently we have collected from a number of localities in Scotland samples of paramecia which have been identified as Paramecium aurelia from the two small vesicular micronuclei seen to be present in stained preparations. The organisms were collected as follows: stock no. 503, St Margaret's Loch, Edinburgh; no. 504, Figgate's Pond, Edinburgh; no. 505, Strathblane, near Glasgow (all November 1952); no. 506, canal at Kingsknowe, Edinburgh; no. 507, canal at Colinton, Edinburgh (February 1953); no. 509, canal at Ratho Park, Edinburgh (March 1953); no. 510, Blackford Pond, Edinburgh (October 1953). Cultures were established by multiplication of a single organism from each stock collected, and in course of time conjugation was seen to occur within such cultures. Tests showed that the same two mating-types were present in all these stocks, but none of the organisms of these two mating types could be induced to show the agglutinative mating reaction, even weakly, with organisms of any of the eight known varieties. Hence, the stocks listed in Table 1 were placed in a new variety of $\boldsymbol{P}$. aurelia-variety 9 , which forms the two mating types XVII and XVIII.

Analysis of ex-conjugants showed that the inheritance of mating-type is of the kind named by Sonneborn (see 1947) caryonidal, that is, from each pair of conjugating organisms, four caryonides are formed by a single division of the ex-conjugants, and the mating-types of all organisms within a caryonide 
are the same. Different caryonides may, however, be of different mating-types. By its manifestation of caryonidal inheritance of mating-type, variety 9 is classified amongst the group $A$ varieties (nos. 1, 3, 5 and 7) of Paramecium aurelia.

From one group of conjugants which had been kept at $25^{\circ}$, twenty-five caryonides were obtained of one mating-type, and fifteen of the other matingtype, which accords well enough with Sonneborn's formula of $18 \cdot 4+t / 0 \cdot 51$ for the percentage of mating-types of even number in varieties 1 and $3(t$ being the temperature in degrees Centigrade; Sonneborn, 1947). In view of the absence of any cross-reactions with mating types of other varieties, we arbitrarily denote that mating type which is formed in excess of $\mathbf{5 0} \%$ after conjugation at $25^{\circ}$ (or higher) as type XVIII, and the other one as type XVII.

Mating of variety 9 organisms will occur when growth has previously been at temperatures between 18 and $\mathbf{2 5}^{\circ}$, though not at higher temperatures, and conjugation has been observed to occur at various times of the day, and after growth in continuous darkness. Lastly, it may be added that the interautogamous period is about 12 days, similar to that found in variety 1.

Variety 9 is the only variety of Paramecium aurelia not yet found in North America.

We wish to thank Dr R. V. Dippell for cytological help in this work.

\section{REFERENCES}

Sonnebonn, T. M. (1938). Mating types in Paramecium aurelia: diverse conditions for mating in different stocks; occurrence, number and interactions of the types. Proc. Amer. phil. Soc. 79, 411.

SonNEBorn, T. M. (1942). More mating types and varieties in Paramecium aurelia. Anat. Rec. 73, 390.

Sonneborn, T. M. (1947). Recent advances in the genetics of Paramecium and Euplotes. Advanc. Genet. 1, 264.

SonNeborn, T. M. \& Dippelu, R. V. (1946a). Mating reactions and conjugation between varieties of $P$. aurelia in relation to conceptions of mating type and variety. Physiol. Zool. 19, 1.

Sonneborn, T. M. \& Dippell, R. V. $(1946 b)$. The significance of race 31 as a link between group A and group B varieties of Paramecium aurelia. Anat. Rec. 96, 19.

Wenrich, D. H. (1928). Eight well-defined species of Paramecium. Trans. Amer. micr. Soc. 47, 275.

(Received 15 January 1954) 